Elsevier required licence: (c) <2019>. This manuscript version is made available under the CC-BY-NC-ND 4.0 license http://creativecommons.org/licenses/by-nc-nd/4.0/

The definitive publisher version is available online at https://doi.org/10.1016/j.ctcp.2019.02.008 


\section{Accepted Manuscript}

The prevalence, characteristics, expenditure and predictors of complementary medicine use in Australians living with gastrointestinal disorders: A cross-sectional study

Wei C. Gan, Lorraine Smith, Erica McIntyre, Amie Steel, Joanna E. Harnett

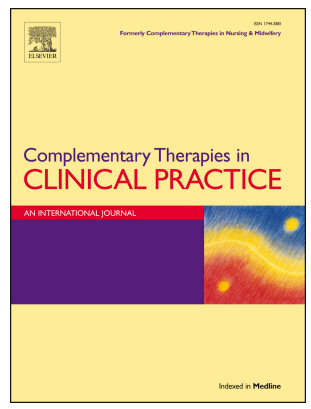

PII:

S1744-3881(18)30719-9

DOI:

https://doi.org/10.1016/j.ctcp.2019.02.008

Reference: CTCP 988

To appear in: Complementary Therapies in Clinical Practice

Received Date: 22 November 2018

Accepted Date: 6 February 2019

Please cite this article as: Gan WC, Smith L, Mclntyre E, Steel A, Harnett JE, The prevalence, characteristics, expenditure and predictors of complementary medicine use in Australians living with gastrointestinal disorders: A cross-sectional study, Complementary Therapies in Clinical Practice (2019), doi: https://doi.org/10.1016/j.ctcp.2019.02.008.

This is a PDF file of an unedited manuscript that has been accepted for publication. As a service to our customers we are providing this early version of the manuscript. The manuscript will undergo copyediting, typesetting, and review of the resulting proof before it is published in its final form. Please note that during the production process errors may be discovered which could affect the content, and all legal disclaimers that apply to the journal pertain. 


\section{The prevalence, characteristics, expenditure and predictors of complementary medicine use in Australians living with gastrointestinal disorders: A cross-sectional study}

Authors: Wei C Gan ${ }^{\mathrm{a}}$; Lorraine Smith ${ }^{\mathrm{a}}$; Erica McIntyre ${ }^{\mathrm{b}}$; Amie Steel ${ }^{\mathrm{b}}$; Joanna E Harnett ${ }^{\mathbf{a}, \mathbf{b}}$

${ }^{a}$ The University Sydney School of Pharmacy, Faculty of Medicine and Health, The University of Sydney, 2006 NSW, Australia; ${ }^{\mathbf{b}}$ The Australian Research Centre in Complementary and Integrative Medicine (ARCCIM), Faculty of Health, University of Technology Sydney, 2007 NSW, Australia

\section{Corresponding Author}

Name: Joanna E Harnett

Phone number: +61293517009

Fax number: +61293514391

Email address: joanna.harnett@sydney.edu.au

Address: The University of Sydney, Building A15, Science Rd, Camperdown NSW 2006, Australia

Total number of words: 5058

Total number of references: 60 


\title{
The prevalence, characteristics, expenditure and predictors of complementary medicine use in Australians living with gastrointestinal disorders: A cross-sectional study
}

\begin{abstract}
Aims: To determine the prevalence, characteristics, expenditure and predictors of complementary medicine (CM) use in Australian adults living with gastrointestinal disorders (GID).

Methods: A cross-sectional study involving 2,025 Australian adults was conducted. Participants were recruited through purposive convenience sampling. Descriptive statistics were conducted to report the prevalence of people living with GIDs and their CM use, including CM products, mindbody practices and CM practitioner services. Chi-square test and independent-samples t-test were used to determine the associations between sociodemographic or health-related variables with $\mathrm{CM}$ use. Binary logistic regression was conducted to determine the significant predictors of CM use in GID participants. Economic data was calculated based on the mean out-of-pocket expenditure on CM.
\end{abstract}

Results: Of the 293 participants reporting a GID, 186 (63.5\%) used CM products, 55 (18.8\%) used a mind-body practice and $141(48.1 \%)$ visited at least one CM practitioner in the last 12 months. Collectively, the majority of GID participants using any type of CM were female, aged 40 to 49 years, married and employed. The mean score for health-related quality of life was 49.6 out of 100 in GID participants and 68.2 in participants without a GID ( $p<0.001)$. Average annual out-of-pocket expenditure on CM products was AUD127.29 by CM products users with a GID. The predictors of $\mathrm{CM}$ products, mind-body practices and $\mathrm{CM}$ practitioner services use differed. Of the $111 \mathrm{CM}$ product users with a GID, $103(92.8 \%)$ disclosed all or some of their CM use to general practitioner, $89(80.2 \%)$ to specialist doctor, $79(71.2 \%)$ to pharmacist and $69(62.1 \%)$ to hospital doctor.

Conclusions: A substantial proportion of Australian adults living with GID use CM products, mindbody practices and CM practitioner services. This study provides important insights to inform and guide the development of a more coordinated health care services for individuals living with GID.

Keywords: Complementary medicine, gastrointestinal disorders, prevalence, characteristics, expenditure, predictors 


\section{Introduction}

An estimated $50-70 \%$ of Australian adults ${ }^{1,2}$ integrate complementary health approaches into their health care management. Complementary health approaches are broadly categorised into natural products, mind-body practices and may involve seeking the professional services of complementary medicine practitioners. ${ }^{3,4}$ The terms used to describe natural products vary around the world. Natural products such as herbal preparations, nutritional supplements, vitamins, minerals, homeopathic medicines and aromatherapy products are classified as complementary medicine (CM) products by the Australian Therapeutic Goods Administration. ${ }^{5}$ Mind-body practices include yoga, tai chi, meditation and relaxation therapy. ${ }^{5}$ Both $\mathrm{CM}$ products and mind-body practices are predominantly self-selected and used in the prevention, treatment or management of illness. ${ }^{3-5}$ In Australia, there is also a range of $\mathrm{CM}$ practitioners who provide $\mathrm{CM}$ health services. CM practitioners predominantly belong to professional associations that act as self-regulatory organisations. ${ }^{6,7}$ An exception to this largely self-regulated CM profession is the inclusion of Chinese Medicine practitioners, chiropractors and osteopaths on the Australian Health Practitioner Regulation Agency (AHPRA). ${ }^{8}$ For the purpose of this paper, the term CM refers to CM products, mind-body practices and CM practitioner services.

While it is well established that complementary approaches to health care are used by a substantial number of Australians, ${ }^{1,2}$ less is known about the sociodemographic and health-related characteristics of people living with specific conditions. ${ }^{2,9}$ Gastrointestinal disorders (GIDs) are common among Australian population ${ }^{10,11}$ and are broadly categorised as functional GIDs (FGIDs) and organic GIDs. FGIDs are the most prevalent gastrointestinal health disorders and they include irritable bowel syndrome (IBS), functional dyspepsia (FD) and functional constipation. ${ }^{10,11}$ The prevalence of organic gastrointestinal diseases has increased over the last decade, ${ }^{10,12}$ including gastroesophageal reflux disease (GERD), coeliac disease and inflammatory bowel diseases (IBD) such as Crohn's disease (CD) and ulcerative colitis (UC).

A recent systematic review ${ }^{13}$ that included studies conducted in the last decade reported that $27-58 \%$ of Australian adults ${ }^{14-16}$ living with medically diagnosed GIDs used CM. The results of the aforementioned review ${ }^{13}$ identified that this prevalence data ${ }^{14-16}$ were possibly no longer current and predominantly reported on CM products use. Therefore, there is a need for current and 
comprehensive data on CM use by this population. ${ }^{13}$ The aims of this study were to provide current data on the prevalence, sociodemographic and health-related characteristics as well as out-of-pocket expenditure of CM use in Australian adults living with a GID. This study also aims to determine the predictors of $\mathrm{CM}$ products, mind-body practices and CM practitioner services use in this population.

\section{Methods}

\subsection{Study design}

A cross-sectional online survey involving Australian adults aged 18 years or above was conducted.

\subsection{Settings}

The participants were recruited through purposive convenience sampling from an existing Australian database (Qualtrics ${ }^{\mathrm{TM}}$ ) of adults who had registered their interest to participate in research. Members of the database were invited via email with the link to complete the online survey. Informed consent was obtained from the participants. A small financial incentive was provided to the participants in return for completing the online survey that took approximately 10 to 15 minutes. The recruitment of participants and collection of data took approximately one month starting from $26^{\text {th }}$ July until $28^{\text {th }}$ August 2017.

\subsection{Outcome measures}

The survey questionnaire was comprised of questions related to the sociodemographic characteristics, health-related characteristics, CM use, conventional health service utilisation and communication of CM use to health care professionals (HCPs).

\subsubsection{Sociodemographic characteristics}

Participants were asked to provide their sociodemographic characteristics such as age, gender, postcode of residence, education level, marital status, financial manageability, employment and private insurance status.

\subsubsection{Health-related characteristics}

Participants were asked to indicate any diagnosed or treated chronic condition in the past three years from a list of 30 chronic conditions within the Australian National Health Priority Areas (NHPA). ${ }^{17}$ Participants were also provided with the option to indicate an 'other health condition' and specify the condition, or an option to answer 'none of the above' to indicate no diagnosed or treated chronic illness. Seven items based on the Short Form-20 (SF-20) of a medical outcomes study ${ }^{18}$ were used to measure the health-related quality of life (HRQOL) of participants by asking them to rate their health status on a 5-point Likert scale ranging from poor (1 point) to excellent (5 points). The questions on participant's HRQOL were comprised of seven domains such as general 
health status, physical functioning, experience of bodily pain in the past four weeks, role functioning, mental health and current health perception. The total score of all the seven items was used to calculate the mean in which higher mean score reflects better CM health literacy.

Furthermore, the 21 items of the Montana State University (MSU) Complementary and Alternative Medicine Health Literacy Scale (CAMHLS) ${ }^{19}$ were reviewed and modified by content experts for use in measuring the health literacy on herbal medicine and vitamins or mineral supplements among the Australian population. The scale items included five response options ranging from 1 (agree strongly) to 5 (disagree strongly). Twelve of the 21 items were reverse scored to ensure all responses were in a positive direction. Subsequently, the total score of all the 21 items was used to calculate the mean in which higher mean score reflects better CM health literacy.

\subsubsection{Utilisation of complementary and conventional health service and medicinal products}

Questions related to the use of CM products, mind-body practices and CM health services were developed based on the International Complementary and Alternative Medicine Questionnaire (I-CAM-Q), ${ }^{20}$ which has been validated in a number of population samples. ${ }^{20,21}$ I-CAM-Q requires country specific items that are relevant to the population study to be added into the survey questions. $^{22}$ Therefore, the I-CAM-Q was adapted in this study for use within the cultural context of the Australian population. The survey participants were asked to indicate their CM use over the last 12 months from a list of CM products, mind-body practices and CM practitioners, followed by their estimated out-of-pocket expenditure for each CM used.

Furthermore, participants were asked to provide information about their conventional health service utilisation over the last 12 months such as the type of HCPs visited and estimated out-ofpocket cost for each consultation. Participants were also asked to indicate if they used pharmaceutical medicines on a daily basis through a dichotomous (yes or no) response. If answering yes to this question, the participants were asked to specify the health condition that the medicine was taken to treat.

\subsubsection{Disclosure of CM products use to HCPs}

Participants were asked to indicate their disclosure of $\mathrm{CM}$ products use to conventional HCPs over the last 12 months by selecting one of the four response options that were "told HCPs about all CM use", "told HCPs about some of the CM use", "did not tell HCPs" and "did not visit this HCP". The HCPs listed were general practitioner (GP), specialist doctor, hospital doctor and pharmacist.

\subsection{Statistical analysis}


Data were cleaned prior to analysis using Statistical Package for the Social Science (SPSS) statistics version 24. ${ }^{23}$ Data were also weighed against the Australian Bureau of Statistics (ABS) data in year 2016 with respect to age, gender and state of residence by using a Chi-square test of association. ${ }^{24}$ Descriptive statistics were conducted to report the prevalence data on participants' sociodemographic characteristics, health-related variables and CM use. Binary variables (yes or no) were created from the categorical variables that related to GID and each type of CM use. For the purpose of analysis, participants who reported being medically diagnosed or being treated with a GID within the past three years will be referred to as the GID group, whilst those not reporting a GID will be referred to as the no-GID group. In addition, $\mathrm{CM}$ users were divided into $\mathrm{CM}$ product users, mind-body practice users and CM practitioner service users.

Chi-square test of association ${ }^{23}$ was conducted to determine the statistical significance of the associations between categorical sociodemographic or health-related variables between the comparison groups. The first comparison group was GID participants versus participants without a GID, whereas the other comparison groups were between those CM and non-CM users in the GID group. Independent samples t-tests ${ }^{23}$ were conducted to compare the mean scores of HRQOL and CAMHLS (herbal medicine and minerals/supplements) between the comparison groups, whilst Levene's test ${ }^{23}$ was used to determine the homogeneity of variance across the data. Statistical significance was assumed as p-value less than 0.05 ( $p<0.05)$. In addition, sociodemographic and health-related variables with $\mathrm{p}<0.05$ or theoretical importance were included in a stepwise backward binary logistic regression analysis ${ }^{25}$ to determine the statistically significant predictors of CM products, mind-body practices and CM practitioner services use in GID participants. HosmerLemeshow test ${ }^{26}$ was conducted to determine the goodness of fit for the logistic regression model.

Economic data were calculated based on the mean out-of-pocket expenditure on each type of $\mathrm{CM}$ as well as conventional health services and medicines utilisation in participants with and without a GID. Subsequently, independent-samples t-tests ${ }^{23}$ were conducted to determine the significant difference in the mean out-of-pocket expenditure between these two groups. Economic calculations of population level out-of-pocket expenditure were based on the Australian census figures for 2016 for Australian adults aged 20 years or above $(n=17,615,676)^{24}$ and the reported prevalence of GID in this study. These two figures were then multiplied to give the estimated number of the Australian population with a GID, which was further extrapolated from the reported mean expenditure by GID participants in this study to obtain the estimated total expenditure by Australian population with a GID.

\subsection{Ethics}


This study was approved by the Human Research Ethics Committee (EC00358) at Endeavour College of Natural Health in accordance with the Declaration of Helsinki.

\section{Results}

Of the 2,025 survey respondents, six respondents' data with no variance were removed after initial screening due to the concerns of data reliability, resulting in a final 2,019 complete responses. The demographic profile of the participants was representative of the Australian population in terms of age, gender and state of residence when compared to the ABS data in year $2016(\mathrm{p}>0.05) .{ }^{24} \mathrm{~A}$ total of $1,057(52.3 \%)$ of the 2,019 participants reported using at least one type of CM within the last 12 months, whilst 293 participants (14.5\%) reported at least one medically diagnosed GID within the past three years. Of the 293 participants reporting a diagnosed GID, $186(63.5 \%)$ used CM products, $55(18.8 \%)$ used mind-body practices, and $141(48.1 \%)$ visited one or more CM practitioners. Among the GID group ( $n=293)$, the most prevalent type of GID reported was GERD $(44.0 \%)$, followed by IBS (35.5\%), whilst the least prevalent was celiac disease $(6.1 \%)$.

\subsection{Sociodemographic and health-related characteristics of participants with and without a GID}

As presented in Table 1, participants with a GID $(n=293)$ were predominantly female $(69.3 \%)$, in a marital relationship (43.3\%) and over 60 years of age $(29.4 \%)$. Whilst the majority (36.9\%) held an apprenticeship/certificate/diploma qualification. Among participants with a GID, less than half $(47.1 \%)$ were in the paid work force (versus $58.5 \%$ in no-GID group; $\mathrm{p}<0.001$ ), whilst more than half $(68.9 \%)$ reported financial difficulty at some or all of the time (versus $57.6 \%$ in noGID group; $\mathrm{p}<0.001)$. However, no significant difference was found in holding private health insurance (PHI) between participants with a GID (50.2\%) and those without $(51.0 \%$; $=0.782)$.

\section{INSERT TABLE 1 HERE}

Table 2 shows that over half $(57.7 \%)$ of the GID participants reported to have mental health disorder (versus $27.3 \%$ in no-GID group; $\mathrm{p}<0.001$ ), whereas $38.2 \%$ had musculoskeletal disorder (versus $11.9 \%$ in the no-GID group, $\mathrm{p}<0.001$ ). The mean HRQOL score in GID group was 49.60 out of 100, which was significantly lower than the score of 68.23 in no-GID group $(p<0.001)$. The mean scores of CAMHLS on herbal medicine was 3.72 out of 5 among participants with a GID (versus 3.59 in the no-GID group; $\mathrm{p}<0.001$ ), whilst the mean score of CAMHLS on vitamins or mineral supplements was 3.74 out of 5 in GID group (versus 3.56 in the no-GID group; $\mathrm{p}<0.001$ ) 
Table 1 also summarises the results of the sociodemographic characteristics of CM and non$\mathrm{CM}$ users in the GID group. The use of CM was divided into three categories including CM products, mind-body practices and CM practitioner services. Across all three groups of CM users, the majority were female, aged between 40-49 years, married and employed (Table 1). The most common highest qualification they reported was a certificate/apprenticeship/diploma, whilst the least common was a year 12 qualification (Table 1). Irrespective of the CM used, more than half reported financial difficulty at some or all of the time. Chi-square tests of association identified gender, age, employment and marital status were all significantly associated with CM product use $(\mathrm{p}<0.05)$, whereas marital status and age were significantly associated with mind-body practice use $(\mathrm{p}<0.05)$. In addition, age was the only significant factor associated with visiting a CM practitioner $(\mathrm{p}<0.05)$.

As presented in Table 2, a significant association was identified between CM products use and anxiety disorder $(\mathrm{p}=0.038)$. GID participants who used CM products were less likely to report anxiety disorder $(30.1 \%)$ than non-CM products users with a GID (42.1\%). There was no significant difference between any of the three CM approaches used with the HRQOL scores ( $p>0.05$ ). The mean score of CAMHLS on vitamins and mineral supplements was 3.68 out of 5 in GID participants who used CM practitioner services, which was significantly lower than that of non-CM practitioner service users with a GID (3.78 out of $5 ; \mathrm{p}=0.024)$.

3.3. Prevalence of complementary and conventional health services and medicinal products utilisation by participants with and without a GID

As shown in Table 3, participants living with a GID were more likely to visit any of the conventional HCPs than those without a GID $(\mathrm{p}<0.001)$. The results revealed that nearly all of the GID participants $(97.3 \%$ ) had consulted a GP in the previous 12 months. Whilst the prevalence of consultation with community or hospital pharmacists were $89.1 \%$ in GID group (versus $74.3 \%$ in no-GID group; $\mathrm{p}<0.001)$. In relation to $\mathrm{CM}$ practitioner services, there were significant differences identified in the prevalence of consultation with massage therapists, chiropractors, acupuncturists and osteopaths in GID group as compared to no-GID group $(\mathrm{p}<0.05)$.

Of the CM products, significant associations were identified between the presence of GID with the use of vitamins or mineral supplements, homeopathy and flower essences $(p<0.005)$ as presented in Table 3. Specifically, the use of vitamins or mineral supplements was significantly higher in participants with a GID $(61.1 \%)$ than those without a GID $(45.6 \%$; p <0.001). The prevalence of yoga or tai chi use was significantly lower in the GID group (7.2\%) as compared to no-GID group $(12.5 \%$; $\mathrm{p}=0.009)$. In term of conventional medicines, the uses of both prescription- 
only and over-the-counter medicines were significantly higher in the GID group $(90.8 \%$ and $78.2 \%$ respectively) than no-GID group $(71.6 \%$ and $64.9 \%$ respectively; $\mathrm{p}<0.001)$.

\section{INSERT TABLE 3 HERE}

3.4. Out-of-pocket expenditure on complementary and conventional health services and medicinal product by participants with and without a GID.

Table 4 presents the reported out-of-pocket expenditure for each health service and medicinal product used by the GID and no-GID groups over the last 12 months. The mean expenditure on CM products varied across each category and there was no significant difference for the mean out-of-pocket expenditure on CM products between GID and no-GID groups ( $p>0.05$ ). Mind-body practice users with a GID had a mean expenditure on yoga or tai chi of AUD10.56 (versus AUD37.82 in mind-body practice users without a GID; $\mathrm{p}=0.044$ ). Of all the health practitioner services, only expenditure on yoga teachers was significantly lower in GID group (AUD5.40 per CM practitioner service user) compared to the no-GID group (AUD15.77 per CM practitioner service user; $\mathrm{p}=0.045)$. In addition, CM product users with a GID spent AUD197.92 and AUD71.09 on prescription-only and over-the-counter medicines respectively, which were significantly higher than CM product users without a GID (AUD105.53 and AUD48.19 respectively; $\mathrm{p}<0.005)$.

Extrapolating from the available national figures ${ }^{24}$ in year 2016, and assuming an average individual out-of-pocket expenditure in line with that of the GID participants from this study, the estimated total out-of-pocket expenditures on CM products, CM practitioner services and mindbody practices in Australian adults aged 20 years or above living with a GID $(n=2,556,411)$ were approximately AUD207.7 million, AUD259.3 million and AUD16.6 million per annum respectively.

\section{INSERT TABLE 4 HERE}

3.5. Predictors of CM products, mind-body practices and CM practitioner services utilization in participants living with a GID

Table 5 shows that the significant predictors of CM products use by those with a GID were being female and employed $(\mathrm{p}<0.05)$. The results also revealed that the predictors of mind-body practices use were being younger and having a higher education qualification $(\mathrm{p}<0.05)$, whilst lower HRQOL and younger age were the significant predictors of CM practitioner services use $(\mathrm{p}<0.05)$. The results of Hosmer-Lemeshow test indicated a good fit in the regression models for CM products $(\mathrm{p}=0.748)$, mind-body practices $(\mathrm{p}=0.587)$ and $\mathrm{CM}$ practitioner services $(\mathrm{p}=0.973)$ as their 
p-values were all more than 0.05 . In addition, the regression model accurately classified $63 \%$ of CM products' cases, $81 \%$ of mind-body practices' cases and $63 \%$ of CM practitioner services' cases.

\section{INSERT TABLE 5 HERE}

\subsection{Disclosure of CM products use to HCPs by CM product users with GID}

A total of $111 \mathrm{CM}$ products users with a GID responded to the disclosure questions with 103 $(92.8 \%)$ disclosed all or some of their CM products use to their GPs, 89 (80.2\%) to specialist doctors, $79(71.2 \%)$ to pharmacists and $69(62.1 \%)$ to hospital doctors (Figure 1). The most common reasons provided by survey participants for disclosing their CM products use ( $\mathrm{n}=103$ ) were that they wanted their HCPs to fully understand their health status (95.1\%), they concerned about drug-CM interactions $(83.5 \%)$, and that they trusted their HCPs would be able to help with their treatment decisions $(74.8 \%)$. Conversely, the most common reasons provided by survey participants for not disclosing their CM products use $(n=26)$ were that they were not asked by their HCPs $(65.4 \%)$, they thought it was not important to do so (57.7\%), insufficient consultation time with HCPs (50.0\%), and that they were worried about CM use being discouraged (50.0\%).

\section{INSERT FIGURE 1 HERE}

\section{Discussion}

To our knowledge, this is the first study that individually reports the utilisation of each CM approach to health care (CM products, mind-body practices, and CM practitioner services) in an Australian adult population living with a GID. The primary focus of this study was to report and critically evaluate data on CM use in participants with a GID. Meanwhile, valuable insights were also gained into the sociodemographic and health-related characteristics of participants with a GID.

\subsection{Prevalence of CM use and characteristics of GID participants}

Our findings show that CM use ranged from $18.8 \%$ to $63.5 \%$ in participants with a GID, which was higher than those without a GID. This result is consistent with the findings of a recent systematic review ${ }^{13}$ that reported the use of both $\mathrm{CM}$ products and mind-body practices in Australian adults living with medically diagnosed GID ranged from $27 \%$ to $58 \%{ }^{14-16}$ In terms of sociodemographic and health-related characteristics, people living with a GID were more likely to be female, older in age, unemployed, reporting financial stress, have a low HRQOL and have a high incidence of comorbid conditions such as mental health and musculoskeletal disorders. These findings may suggest that the GID population have significant social and psychological burdens. 
The effects of these burdens may also be reflected in the higher prevalence of conventional HCPs consultations and pharmaceutical medicines used by this population. Together with the high reported out-of-pocket expenditure on conventional medicines, the impact of this cluster of conditions may place a substantial burden not only on the 'public purse' but also on these individuals and their household budgets. From a clinical perspective, the high concomitant use of both $\mathrm{CM}$ products and conventional medicines in the GID population raises important considerations about the potential risk of adverse drug interactions. Meanwhile, the high prevalence of both conventional and $\mathrm{CM}$ practitioner consultations highlights the need for initiatives that facilitate the inter-professional communication between these health practitioners. Such initiatives would contribute to the integration of patients' preferences into a more coordinated model of care that encourages a safer and more appropriate use of both CM and conventional medicines.

\subsection{Sociodemographic and health-related characteristics of CM users with a GID}

The sociodemographic factors of participants with a GID who use all three types of CM approaches (CM products, mind-body practice and CM practitioner service) are similar to an earlier Australian study that identified female CM users in the general population were more likely to be middle-aged with a higher education and annual income compared to females who did not use CM. ${ }^{9}$ It has been suggested that a higher education level was associated with a higher level of health literacy, ${ }^{27,28}$ better access to CM resources, ${ }^{27,28}$ greater ability for self-determination, ${ }^{29}$ and a higher disposable income to spend on $\mathrm{CM}^{30}$ If these explanations apply to the participants with a GID in this study, it may suggest that they independently assess information and select self-determined health approaches to address their GI complaints. Together with the high prevalence of conventional medicines use in a GID population, this 'self-selecting' process may result in a lack of professional guidance about the appropriate use of $\mathrm{CM}$ products, thereby increasing the risk of adverse interactions between conventional medicines and CM products.

In addition, this study found that both $\mathrm{CM}$ product and $\mathrm{CM}$ practitioner service users in the GID group were less likely to report financial difficulties compared to those not using these two $\mathrm{CM}$ approaches. This finding may suggest that people with a GID will be more likely to use CM products or visit a CM practitioner for their gastrointestinal symptoms when they are more financially capable. The lower prevalence of anxiety disorder in CM product users with a GID does not align with the findings from previous studies ${ }^{31-33}$ that reported CM use was higher in individuals with anxiety symptoms. Given the high prevalence of reported anxiety disorder in participants with a GID, the beneficial effects of certain CM products in alleviating gastrointestinal symptoms may possibly provide a calming effect that reduces the anxiety symptoms. However, the association between $\mathrm{CM}$ products use with the prevalence of anxiety disorder warrants further research attention. 


\subsection{CM products use in participants with a GID}

The higher prevalence of CM products use and associated out-of-pocket expenses on CM products such as vitamins and mineral supplements in those with a GID compared to those without is also noteworthy, especially given the fact that GID participants were more likely to report financial difficulty than those without a GID. Furthermore, the higher prevalence of comorbidities and lower HRQOL in GID participants also indicate the substantial social and psychological impact of living with a GID. Despite this, the GID participants were still willing to carry the out-of-pocket expenses associated with $\mathrm{CM}$ products use. However, the factors that drive the use of CM products in people living with a GID in this study cannot be ascertained. While speculative, CM products use may be associated with the prevention or treatment of nutritional deficiencies due to the malabsorption characteristics of some GIDs. ${ }^{34}$ This speculation is based on the evidence that suggests those with IBD may be at an increased risk of specific nutrient deficiencies such as iron, vitamins $\mathrm{B}_{1}$ and $\mathrm{D}^{34-37}$ and those with conditions associated with diarrhoea at risk of zinc, potassium and magnesium depletion. ${ }^{38}$ Unlike vitamins or mineral supplements, our study revealed that both prevalence and expenditure of Western or Chinese herbal medicines use were lower in GID group, which is inconsistent with previous literature ${ }^{14-16}$ and may be related to the under-reporting by the survey participants. Despite the lower rates of herbal medicines use in this study, herbal medicines were still being used by a proportion of people living with specific types of GIDs. Such use may be associated with the growing body of evidence to support the use of specific herbal medicines such as enteric-coated peppermint oil capsules and herbal preparation STW-5 (Iberogast ${ }^{\mathrm{TM}}$ ) in the management of IBS. ${ }^{39,40}$ Given the clinical challenges with effectively managing IBS, there is a scope for coordinated integration of herbal medicines into the conventional care.

\subsection{CM practitioner visits in participants with a GID}

The finding that massage therapists were the most common practitioner visited may reflect the broader complex clinical picture that involves comorbid conditions or simply a stress reduction intervention. It is well known that stress is associated with the exacerbation of IBS symptoms. ${ }^{10,41}$ The association between the brain and gastrointestinal tract has emerged to have a substantial influence in people living with IBS. ${ }^{10,41}$ There is also some evidence to support the efficacy of massage techniques in managing gastrointestinal symptoms such as cramping, bloating and constipation. ${ }^{42,43}$ The higher prevalence of acupuncturist visits by GID participants in this study may be associated with the evidence to support the efficacy of specific acupuncture techniques in the management of IBS, constipation, diarrhoea, nausea and vomiting. ${ }^{44,45}$ Despite the prevalence of chiropractor and osteopath consultations was higher in GID participants, the available evidence is limited to support the role of chiropractic and osteopathic treatments in the management of GIDs. ${ }^{46,47}$ It is more likely that this result can be explained by the higher prevalence of reported 
musculoskeletal disorders amongst GID participants. Given the fact that people with GIDs are using $\mathrm{CM}$ practitioner services, it is important to ensure such CM practitioners are competent in their clinical management of GIDs and refer people with GIDs who present with 'red flag' signs or symptoms to conventional HCPs for appropriate care.

\subsection{Mind-body practices use in participants with a GID}

Our study found that the prevalence of using yoga or tai chi was lower in GID participants despite previous studies ${ }^{48-50}$ reported the effectiveness of such practices in alleviating bloating and constipation as well as reducing stress and anxiety associated with IBS. This is possibly associated with the higher rate of comorbidities and lower HRQOL in GID participants that potentially affect their physical functioning to carry out such practices. Similarly, there was no difference identified in the prevalence of using relaxation or meditation therapies between GID and no-GID groups despite the beneficial roles of these therapies in managing gastrointestinal symptoms. ${ }^{51,52}$ Hence, further research is needed to explore the trend of using mind-body practices in GID population and understand the reason for their decision making in selecting such practices.

4.6. Predictors of CM products, mind-body practices and CM practitioner services use in GID group

The unique focus of this study in reporting the predictors for each CM approach use in GID population allows a more in-depth evaluation. The analysis identified that while GID participants who were female and employed had significantly increased odds of using CM products, education level was not a significant predictor of CM product use. Consequently, this brings earlier studies ${ }^{9,30}$ that claimed education as one of the predictor for CM use into question, and may suggest that our finding is unique to the specific cohort in the population with a GID. Furthermore, it is interesting that younger age and higher education level were the significant predictors of mind-body practices use in GID participants, whereas GID participants with a lower HRQOL and younger age were more likely to visit a CM practitioner. The lower HRQOL in CM practitioner service users possibly suggests that GID participants with a lower HRQOL have unmet health needs from the conventional health professionals alone.

\subsection{Disclosure of CM products use to conventional HCPs}

Previous studies reported that Australians' disclosure of CM use to conventional HCPs was poor with the disclosure rate ranging from $47 \%$ to $60 \%$ in year $2012 .{ }^{53}$ However, our study shows an encouraging result on the disclosure rate of $\mathrm{CM}$ products use to conventional HCPs, which ranged from $62.1 \%$ to $92.8 \%$ depending on the HCP consulted. This finding suggests a positive trend in GID patients wanting their HCPs to be aware of their CM use and monitor for any potential interactions between conventional and complementary medicines. ${ }^{54}$ The high $\mathrm{CM}$ products disclosure rate may also be associated with the increased efforts by the professional associations 
such as Australian Medical Association (AMA) in encouraging GPs to be proactive in asking patients about CM use. ${ }^{55}$ Furthermore, participants with a GID were less likely to disclose their CM products use to pharmacists than other HCPs. Given the vast majority of CM products are sold through community pharmacies, the higher prevalence of non-disclosure to pharmacists remains a concern with the increasing reports of side effects of CM products use ${ }^{56-58}$ and other issues such as contamination of CM products. ${ }^{59}$ Together with the common reasons for non-disclosure identified in this study, it is important to ensure that pharmacists allow sufficient consultation time to engage in such inquiry. ${ }^{60}$

\subsection{Limitations of study}

The findings of this study should be interpreted and contextualised within certain limitations related to the study design. The survey data were vulnerable to recall bias due to the reliance of selfreporting by the participants. In particular, data such as expenditure should be treated as estimates of true values. The risk of recall bias was minimised by shortening the recall period specifically to 12 months for all the conventional and complementary health services and medicinal products uses. The study design was subjected to sampling bias as a consequence of purposive convenience sampling method. In order to reduce the impact of sampling bias, the demographic profile of the study's participants was compared to the ABS data ${ }^{24}$ in year 2016. To ensure the integrity of our data, the tools or instruments employed in the development of survey questionnaire had been validated in a number of population samples and they were reviewed by content experts such as CM practitioners, statisticians and health service researchers to ensure the cultural relevance and appropriateness of their use in the Australian population. ${ }^{18-22}$

\section{Conclusion}

A substantial proportion of people living with a GID use CM products, mind-body practices and CM practitioner services. The findings of this study provide an important insight into the sociodemographic and health-related characteristics of Australian adults living with a GID and their $\mathrm{CM}$ use. These findings can be used to guide the clinical care provided by both conventional HCPs and CM practitioners to people living with GIDs. Future research is warranted to explore the use of specific types of $\mathrm{CM}$ products in people living with specific GIDs to ensure a safer and more coordinated health care.

\section{Acknowledgements}

The authors would like to thank the participants for their contribution of time and effort in completing the survey. The authors would also like to thank Endeavour College of Natural Health 
and the Australian Research Centre in Complementary and Integrative Medicine (ARCCIM) for providing access to the data set used in this study. The Sydney Pharmacy School, Faculty of Medicine and Health is thanked for providing infrastructure support for Mr Wei C Gan.

\section{Conflict of interest}

The authors declare no conflicts of interest.

\section{Funding}

This study was funded by Endeavour College of Natural Health and the Australian Research Centre in Complementary and Integrative Medicine (ARCCIM) at University of Technology Sydney.

\section{Author Contributions}

This paper is the Honours thesis of WG. JH, EM, and AS contributed to the study design and development of the survey instrument. WG developed the analysis plan and conducted the analysis that was critically reviewed by LS and JH. WG prepared the manuscript, which was critically reviewed by JH, LS, EM and AS. JH, EM and AS provided CM expertise, whereas LS provided social research and statistical expertise.

\section{References}

1. MacLennan AH, Myers SP, Taylor AW. The continuing use of complementary and alternative medicine in South Australia: costs and beliefs in 2004. Medical Journal of Australia 2006;184(1):27-31.

2. Xue CCL, Zhang AL, Lin V, Da Costa C, Story DF. Complementary and alternative medicine use in Australia: a national population-based survey. Journal of Alternative and Complementary Medicine 2007;13(6):643-50.

3. National Center for Complementary and Integrative Health (NCCIH). Complementary, alternative, or integrative health: what's in a name? [Internet] 2017 [cited 2018 November 11]; Available from: https://nccih.nih.gov/health/integrative-health. 
4. The National Institute of Complementary Medicine (NICM). Understanding complementary and integrative medicine. [Internet] 2018 [cited 2018 November 11]; Available from: http://www.nicm.edu.au/health_information/information_for_consumers/understanding_cm.

5. Therapeutic Goods Administration (TGA). Complementary medicines. [Internet] 2018 [cited 2018 November 11]; Available from: https://www.tga.gov.au/complementary-medicines.

6. The National Institute of Complementary Medicine (NICM). Choosing a complementary medicine practitioner. [Internet] 2018 [cited 2018 November 11]; Available from: https://www.nicm.edu.au/health_information/information_for_consumers/choosing_a_complem entary_medicine_practitioner.

7. Naturopaths and Herbalists Association of Australia (NHAA). Regulation of herbalists and naturopaths in Australia. [Internet] 2018 [cited 2018 November 11]; Available from: https://www.nhaa.org.au/mediareleases/be-informed/regulation-of-practitioners.

8. Australian Health Practitioner Regulation Agency (AHPRA). Register of practitioners. [Internet] 2018 [cited 2018 November 11]; Available from: https://www.ahpra.gov.au/Registration/Registers-of-Practitioners.aspx.

9. Reid R, Steel A, Wardle J, Trubody A, Adams J. Complementary medicine use by the Australian population: a critical mixed studies systematic review of utilisation, perceptions and factors associated with use. BMC Complementary and Alternative Medicine 2016;16(1):176-98.

10. Boyce PM, Talley NJ, Burke C, Koloski NA. Epidemiology of the functional gastrointestinal disorders diagnosed according to Rome II criteria: an Australian population-based study. Internal Medicine Journal 2006;36(1):28-36.

11. Australian Institute of Health and Welfare (AIHW). Australian burden of disease study: impact and causes of illness and death in Australia 2011. [Internet] 2016 [cited 2018 November 11]; Available from: https://www.aihw.gov.au/getmedia/35368d4b-675c-4f2a-acfec3f50285fa7d/19662.pdf.aspx?inline=true.

12. Studd C, Cameron G, Beswick L, Knight R, Hair C, McNeil J, et al. Never underestimate inflammatory bowel disease: high prevalence rates and confirmation of high incidence rates in Australia. Journal of Gastroenterology and Hepatology 2016;31(1):81-6.

13. Gan WC, Smith L, Luca EJ, Harnett JE. The prevalence and characteristics of complementary medicine use by Australian and American adults living with gastrointestinal disorders: a systematic review. Complementary Therapies in Medicine 2018;41:52-60.

14. Holt DQ, Strauss BJ, Moore GT. Patients with inflammatory bowel disease and their treating clinicians have different views regarding diet. Journal of Human Nutrition and Dietetics 2017;30(1):66-72. 
15. Mikocka-Walus A, Andrews JM. Attitudes towards antidepressants among people living with inflammatory bowel disease: an online Australia-wide survey. Journal of Crohn's and Colitis 2014;8(4):296-303.

16. Mountifield R, Andrews JM, Mikocka-Walus A, Bampton P. Covert dose reduction is a distinct type of medication non-adherence observed across all care settings in inflammatory bowel disease. Journal of Crohn's and Colitis 2014;8(12):1723-9.

17. Australian Institute of Health and Welfare (AIHW). First report on National Health Priority Areas 1996. [Internet] 2017 [cited 2018 November 11]; Available from: https://www.aihw.gov.au/getmedia/11b6bbee-cfcf-4af0-9d32d303e0d7ee3b/frnhpa96.pdf.aspx?inline=true.

18. Stewart AL, Hays RD, Ware JE. The MOS short-form general health survey: reliability and validity in a patient population. Medical Care 1988;26(7):724-35.

19. Shreffler-Grant J, Weinert C, Nichols E. Instrument to measure health literacy about complementary and alternative medicine. Journal of Nursing Measurement 2014;22(3):489-99.

20. Quandt SA, Verhoef MJ, Arcury TA, Lewith GT, Steinsbekk A, Kristoffersen AE, et al. Development of an international questionnaire to measure use of complementary and alternative medicine (I-CAM-Q). Journal of Alternative and Complementary Medicine 2009;15(4):331-9.

21. Quandt SA, Ip EH, Saldana S, Arcury TA. Comparing two questionnaires for eliciting CAM use in a multi-ethnic US population of older adults. European Journal of Integrative Medicine 2012;4(2):e205-e11.

22. Bryden GM, Browne M. Development and evaluation of the R-I-CAM-Q as a brief summative measure of CAM utilisation. Complementary Therapies in Medicine 2016;27:82-6.

23. Field AP. Discovering statistics using IBM SPSS statistics. 5th ed. London, England; Thousand Oaks, California: Sage Publications; 2018.

24. Australian Bureau of Statistics (ABS). Population by age and sex, Australian states and territories. [Internet] 2016 [cited 2018 November 11]; Available from: http://www.abs.gov.au/AUSSTATS/abs@.nsf/Previousproducts/3101.0Feature\%20Article1Jun $\% 202016$.

25. Hosmer DW, Lemeshow S, Sturdivant RX. Applied logistic regression. 3rd ed. Chichester, England: Wiley; 2013.

26. Paul P, Pennell ML, Lemeshow S. Standardizing the power of the Hosmer-Lemeshow goodness of fit test in large data sets. Statistics in Medicine 2013;32(1):67-80.

27. Wilkinson JM, Simpson MD. High use of complementary therapies in a New South Wales rural community. Australian Journal of Rural Health 2001;9(4):166-71. 
28. Keleher H, MacDougall C. Understanding health: a determinants approach. 2nd ed. South Melbourne, Victoria: Oxford University Press; 2009.

29. Bishop FL, Yardley L, Lewith GT. A systematic review of beliefs involved in the use of complementary and alternative medicine. Journal of Health Psychology 2007;12(6):851-67.

30. Spinks J, Hollingsworth B. Policy implications of complementary and alternative medicine use in Australia: data from the national health survey. Journal of Alternative and Complementary Medicine 2012;18(4):371-8.

31. McIntyre E, Saliba AJ, Wiener KK, Bishop FL. Predicting the intention to use herbal medicines for anxiety symptoms: a model of health behaviour. Journal of Mental Health 2017;12:1-8.

32. McIntyre E, Saliba AJ, Wiener KK, Sarris J. Prevalence and predictors of herbal medicine use in adults experiencing anxiety: a critical review of the literature. Advances in Integrative Medicine 2015;2(1):38-48.

33. McIntyre E, Saliba AJ, Wiener KK, Sarris J. Herbal medicine use behaviour in Australian adults who experience anxiety: a descriptive study. BMC Complementary and Alternative Medicine 2016;16(1):60-71.

34. DeLegge MH. Nutrition and gastrointestinal disease. Totowa, New Jersey: Humana Press; 2008.

35. Masri OA, Chalhoub JM, Sharara AI. Role of vitamins in gastrointestinal diseases. China National Journal of New Gastroenterology 2015;21(17):5191-209.

36. Ferguson LR, Laing B, Marlow G, Bishop K. The role of vitamin D in reducing gastrointestinal disease risk and assessment of individual dietary intake needs: focus on genetic and genomic technologies. Molecular Nutrition and Food Research 2016;60(1):119-33.

37. Ghaly S, Lawrance I. The role of vitamin D in gastrointestinal inflammation. Expert Review of Gastroenterology and Hepatology 2014;8(8):909-23.

38. Schiller LR, Pardi DS, Sellin JH. Chronic diarrhea: diagnosis and management. Clinical Gastroenterology and Hepatology 2016;15(2):182-93.

39. Malfertheiner P. STW 5 (Iberogast) therapy in gastrointestinal functional disorders. Digestive Diseases 2017;35(1):25-9.

40. Khanna R, MacDonald JK, Levesque BG. Peppermint oil for the treatment of irritable bowel syndrome: a systematic review and meta-analysis. Journal of Clinical Gastroenterology 2014;48(6):505-12.

41. Drossman DA, Hasler WL. Rome IV-functional GI disorders: disorders of gut-brain interaction. Gastroenterology 2016;150(6):1257-61.

42. Loving JE. Massage therapy: theory and practice. Stamford, Connecticut: Appleton and Lange; 1999. 
43. Lamas K, Lindholm L, Stenlund H, Engstrom B, Jacobsson C, Medicinska F, et al. Effects of abdominal massage in management of constipation: a randomized controlled trial. International Journal of Nursing Studies 2009;46(6):759-67.

44. Diehl DL. Acupuncture for gastrointestinal and hepatobiliary disorders. Journal of Alternative and Complementary Medicine 1999;5(1):27-45.

45. Hong H. Acupuncture: theories and evidence. Singapore: World Scientific Publishing Company; 2013.

46. Xue CCL, Zhang AL, Lin V, Myers R, Polus B, Story DF. Acupuncture, chiropractic and osteopathy use in Australia: a national population survey. BMC Public Health 2008;8(1):10512.

47. Ernst E. Chiropractic treatment for gastrointestinal problems: a systematic review of clinical trials. Canadian Journal of Gastroenterology 2011;25(1):39-40.

48. Schumann D, Langhorst J, Dobos G, Cramer H. Randomised clinical trial: yoga versus a lowFODMAP diet in patients with irritable bowel syndrome. Alimentary Pharmacology and Therapeutics 2018;47(2):203-11.

49. Korterink JJ, Ockeloen LE, Hilbink M, Benninga MA, Decker-Kocken JM. Yoga therapy for abdominal pain-related functional gastrointestinal disorders in children: a randomized controlled trial. Journal of Pediatric Gastroenterology and Nutrition 2016;63(5):481-7.

50. Watts C, ProQuest. Yoga therapy for digestive health. London, England; Philadelphia, Pennsylvania: Jessica Kingsley Publishers; 2018.

51. Cearley SM, Immaneni S, Shankar P. Irritable bowel syndrome: the effect of FODMAPs and meditation on pain management. European Journal of Integrative Medicine 2017;12:117-21.

52. Christaki M, Yfandopoulou P. Progressive muscle relaxation as treatment option for children or adolescents with functional gastrointestinal disorders. Health Science Journal 2014;8(2):187-92.

53. Thomson P, Jones J, Evans JM, Leslie SL. Factors influencing the use of complementary and alternative medicine and whether patients inform their primary care physician. Complementary Therapies in Medicine 2011;20(1):45-53.

54. Robinson A, McGrail MR. Disclosure of CAM use to medical practitioners: a review of qualitative and quantitative studies. Complementary Therapies in Medicine 2004;12(2):90-8.

55. Australian Medical Association (AMA). AMA position statement: complementary medicine2012. [Internet] 2012 [cited 2018 November 11]; Available from: https://ama.com.au/positionstatement/complementary-medicine-2012.

56. Patel DN, Low WL, Tan LL, Tan MM, Zhang Q, Low MY, et al. Adverse events associated with the use of complementary medicine and health supplements: an analysis of reports in the 
Singapore Pharmacovigilance database from 1998 to 2009. Clinical Toxicology 2012;50(6):4819.

57. Okoronkwo I, Onyia-Pat JL, Okpala P, Agbo, MA, Ndu A. Patterns of complementary and alternative medicine use, perceived benefits, and adverse effects among adult users in Enugu urban, Southeast Nigeria. Evidence-Based Complementary and Alternative Medicine 2014;2014:239372-6.

58. Frenzel C, Teschke R. Herbal hepatotoxicity: clinical characteristics and listing compilation. International Journal of Molecular Sciences 2016;17(5):588-625.

59. Yang HY, Chen PC, Wang JD. Chinese herbs containing aristolochic acid associated with renal failure and urothelial carcinoma: a review from epidemiologic observations to causal inference. Journal of Biomedicine and Biotechnology 2014;2014:569325-9.

60. Ung COL, Harnett J, Hu H. Development of a strategic model for integrating complementary medicines into professional pharmacy practice. Research in Social and Administrative Pharmacy 2018;14(7):663-72. 


\section{Supplementary Data - Tables and Figure}

\section{Table 1}

Sociodemographic characteristics of GID versus no-GID groups, and between CM and non-CM users in the GID group.

\begin{tabular}{|c|c|c|c|c|c|c|c|c|c|c|c|c|c|c|c|c|c|c|c|c|}
\hline \multirow{3}{*}{$\begin{array}{l}\text { Sociodemographic } \\
\text { characteristics }\end{array}$} & \multirow{2}{*}{\multicolumn{2}{|c|}{$\begin{array}{c}\text { No-GID } \\
\text { group } \\
(n=1,726)\end{array}$}} & \multirow{2}{*}{\multicolumn{2}{|c|}{$\begin{array}{l}\text { GID group } \\
(\mathbf{n}=\mathbf{2 9 3})\end{array}$}} & \multirow{3}{*}{ P-value } & \multicolumn{15}{|c|}{ GID group $(n=293)$} \\
\hline & & & & & & \multicolumn{2}{|c|}{$\begin{array}{c}\text { Non-CM } \\
\text { product } \\
\text { users } \\
(n=107)\end{array}$} & \multicolumn{2}{|c|}{$\begin{array}{c}\text { CM product } \\
\text { users } \\
(n=186)\end{array}$} & \multirow[t]{2}{*}{ P-value } & \multicolumn{2}{|c|}{$\begin{array}{l}\text { Non-mind- } \\
\text { body practice } \\
\text { users }(n=238)\end{array}$} & \multicolumn{2}{|c|}{$\begin{array}{c}\text { Mind-body } \\
\text { practice } \\
\text { users } \\
(\mathbf{n}=55)\end{array}$} & \multirow[t]{2}{*}{ P-value } & \multicolumn{2}{|c|}{$\begin{array}{c}\text { Non-CM } \\
\text { practitioner } \\
\text { service users } \\
(\mathbf{n}=152)\end{array}$} & \multicolumn{2}{|c|}{$\begin{array}{c}\text { CM } \\
\text { practitioner } \\
\text { service users } \\
(\mathbf{n}=\mathbf{1 4 1})\end{array}$} & \multirow[t]{2}{*}{$\begin{array}{c}\text { P- } \\
\text { value }\end{array}$} \\
\hline & $\mathrm{n}$ & $\%$ & $\mathrm{n}$ & $\%$ & & $\mathrm{n}$ & $\%$ & $\mathrm{n}$ & $\%$ & & $\mathrm{n}$ & $\%$ & $\mathrm{n}$ & $\%$ & & $\mathrm{n}$ & $\%$ & $\mathrm{n}$ & $\%$ & \\
\hline Gender & & & & & $<0.001^{*}$ & & & & & $0.032 *$ & & & & & 0.348 & & & & & 0.669 \\
\hline Female & 832 & 48.2 & 203 & 69.3 & & 66 & 61.7 & 137 & 73.7 & & 162 & 68.1 & 41 & 74.5 & & 107 & 70.4 & 96 & 68.1 & \\
\hline Male & 894 & 51.8 & 90 & 30.7 & & 41 & 38.3 & 49 & 26.3 & & 76 & 31.9 & 14 & 25.5 & & 45 & 29.6 & 45 & 31.9 & \\
\hline Age (years) & & & & & $<0.001 *$ & & & & 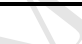 & $0.041^{*}$ & & & & & $0.003^{*}$ & & & & & $0.001^{*}$ \\
\hline $18-29$ & 468 & 27.1 & 44 & 15.0 & & 18 & 16.8 & 26 & 14.0 & & 30 & 12.6 & 14 & 25.5 & & 18 & 11.8 & 26 & 18.4 & \\
\hline $30-39$ & 269 & 15.6 & 44 & 15.0 & & 20 & 18.7 & 24 & 12.9 & & 36 & 15.1 & 8 & 14.5 & & 18 & 11.8 & 26 & 18.4 & \\
\hline $40-49$ & 297 & 17.7 & 65 & 22.2 & & 14 & 13.1 & 51 & 27.4 & & 50 & 21.0 & 15 & 27.3 & & 25 & 16.4 & 40 & 28.4 & \\
\hline $50-59$ & 252 & 14.6 & 54 & 18.4 & & 18 & 16.8 & 36 & 19.4 & & 41 & 17.2 & 13 & 23.6 & & 34 & 22.4 & 20 & 14.2 & \\
\hline 60 and over & 440 & 25.5 & 86 & 29.4 & & 37 & 34.6 & 49 & 26.3 & & 81 & 34.0 & 5 & 9.1 & & 57 & 37.5 & 29 & 20.6 & \\
\hline Employment status & & & & & $<0.001 *$ & & +1 & & & $0.006^{*}$ & & & & & 0.239 & & & & & 0.075 \\
\hline Full time work & 572 & 33.1 & 67 & 22.9 & & 25 & 23.4 & 42 & 22.6 & & 50 & 21.0 & 17 & 30.9 & & 28 & 18.4 & 39 & 27.7 & \\
\hline Part time work & 311 & 18.0 & 59 & 20.1 & & 11 & 10.3 & 48 & 25.8 & & 50 & 21.0 & 9 & 16.4 & & 27 & 17.8 & 32 & 22.7 & \\
\hline Casual work & 127 & 7.4 & 12 & 4.1 & & 2 & 1.9 & 10 & 5.4 & & 8 & 3.4 & 4 & 7.3 & & 5 & 3.3 & 7 & 5.0 & \\
\hline Looking for work & 163 & 9.4 & 22 & 7.5 & & 10 & 9.3 & 12 & 6.5 & & 17 & 7.1 & 5 & 9.1 & & 11 & 7.2 & 11 & 7.8 & \\
\hline Not in paid workforce & 553 & 32.0 & 133 & 45.4 & . & 59 & 55.1 & 74 & 39.8 & & 113 & 47.5 & 20 & 36.4 & & 81 & 53.3 & 52 & 36.9 & \\
\hline Marital status & & & & & $0.034 *$ & & & & & $0.037^{*}$ & & & & & $0.024^{*}$ & & & & & 0.542 \\
\hline Never married & 519 & 30.1 & 65 & 22.2 & 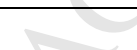 & 30 & 28.0 & 35 & 18.8 & & 56 & 23.5 & 9 & 16.4 & & 32 & 21.1 & 33 & 23.4 & \\
\hline Married & 737 & 42.7 & 127 & 43.3 & & 38 & 35.5 & 89 & 47.8 & & 103 & 43.3 & 24 & 43.6 & & 61 & 40.1 & 66 & 46.8 & \\
\hline De facto (Opposite sex) & 183 & 10.6 & 37 & 12.6 & & 13 & 12.1 & 24 & 12.9 & & 28 & 11.8 & 9 & 16.4 & & 23 & 15.1 & 14 & 9.9 & \\
\hline De facto (Same sex) & 23 & 1.3 & 6 & 2.0 & & 0 & 0.0 & 6 & 3.2 & & 2 & 0.8 & 4 & 7.3 & & 3 & 2.0 & 3 & 2.1 & \\
\hline Separated/divorced/widowed & 264 & 15.3 & 58 & 19.8 & & 26 & 24.3 & 32 & 17.2 & & 49 & 20.6 & 9 & 16.4 & & 33 & 21.7 & 25 & 17.7 & \\
\hline Highest qualification & & & & & $0.046^{*}$ & & & & & 0.429 & & & & & 0.070 & & & & & 0.132 \\
\hline Less than year 12 & 268 & 15.5 & 59 & 20.1 & & 23 & 21.5 & 36 & 19.4 & & 53 & 22.3 & 6 & 10.9 & & 37 & 24.3 & 22 & 15.6 & \\
\hline Year 12 or equivalent & 365 & 21.1 & 56 & 19.1 & & 25 & 23.4 & 31 & 16.7 & & 49 & 20.6 & 7 & 12.7 & & 32 & 21.1 & 24 & 17.0 & \\
\hline
\end{tabular}




\begin{tabular}{|c|c|c|c|c|c|c|c|c|c|c|c|c|c|c|c|c|c|c|c|c|}
\hline Apprenticeship/certificate/diploma & 574 & 33.3 & 108 & 36.9 & & 37 & 34.6 & 71 & 38.2 & & 83 & 34.9 & 25 & 45.5 & & 52 & 34.2 & 56 & 39.7 & \\
\hline University degree & 519 & 30.1 & 70 & 23.9 & & 22 & 20.6 & 48 & 25.8 & & 53 & 22.3 & 17 & 30.9 & & 31 & 20.4 & 39 & 27.7 & \\
\hline Financial manageability & & & & & $<0.001^{*}$ & & & & & 0.901 & & & & & 0.822 & & & & & 0.472 \\
\hline It is difficult all of the time & 343 & 19.9 & 87 & 29.7 & & 34 & 31.8 & 53 & 28.5 & & 69 & 29.0 & 18 & 32.7 & & 51 & 33.6 & 36 & 25.5 & \\
\hline It is difficult some of the time & 651 & 37.7 & 115 & 39.2 & & 42 & 39.3 & 73 & 39.2 & & 94 & 39.5 & 21 & 38.2 & & 57 & 37.5 & 58 & 41.1 & \\
\hline It is not too bad & 616 & 35.7 & 84 & 28.7 & & 29 & 27.1 & 55 & 29.6 & & 70 & 29.4 & 14 & 25.5 & & 40 & 26.3 & 44 & 31.2 & \\
\hline It is easy & 116 & 6.7 & 7 & 2.4 & & 2 & 1.9 & 5 & 2.7 & & 5 & 2.1 & 2 & 3.6 & & 4 & 2.6 & 3 & 2.1 & \\
\hline \multicolumn{21}{|l|}{ Insurance status } \\
\hline Health care card $^{\mathrm{a}}$ & 722 & 41.8 & 117 & 39.9 & 0.542 & 36 & 33.6 & 81 & 43.5 & 0.096 & 96 & 40.3 & 21 & 38.2 & 0.769 & 61 & 40.1 & 56 & 39.7 & 0.942 \\
\hline Private health insurance & 881 & 51.0 & 147 & 50.2 & 0.782 & 58 & 54.2 & 89 & 47.8 & 0.295 & 119 & 50.0 & 28 & 50.9 & 0.903 & 84 & 55.3 & 63 & 44.7 & 0.070 \\
\hline
\end{tabular}

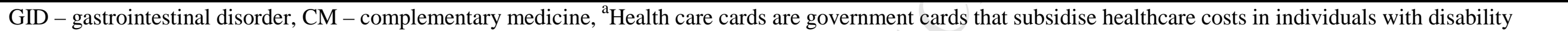

or low socio-economic status, *Indicate a statistically significant difference between the comparison group ( $\mathrm{p}<0.05$ ).

\section{Table 2}

Health-related characteristics of GID versus no-GID groups, and between CM and non-CM users in the GID group.

\begin{tabular}{|c|c|c|c|c|c|c|c|c|c|c|c|c|c|c|c|c|c|c|c|c|}
\hline \multirow{3}{*}{$\begin{array}{l}\text { Health-related } \\
\text { characteristics }\end{array}$} & \multirow{2}{*}{\multicolumn{2}{|c|}{$\begin{array}{c}\text { No-GID } \\
\text { group } \\
(n=1726)\end{array}$}} & \multirow{2}{*}{\multicolumn{2}{|c|}{$\begin{array}{l}\text { GID group } \\
(\mathbf{n}=\mathbf{2 9 3})\end{array}$}} & \multirow{3}{*}{ P-value } & \multicolumn{15}{|c|}{ GID group $(n=293)$} \\
\hline & & & & & & \multicolumn{2}{|c|}{$\begin{array}{c}\text { Non-CM } \\
\text { product users } \\
(\mathbf{n}=\mathbf{1 0 7})\end{array}$} & \multicolumn{2}{|c|}{$\begin{array}{c}\text { CM product } \\
\text { users } \\
(n=186)\end{array}$} & \multirow[t]{2}{*}{ P-value } & \multicolumn{2}{|c|}{$\begin{array}{l}\text { Non-mind- } \\
\text { body practice } \\
\text { users }(n=238)\end{array}$} & \multicolumn{2}{|c|}{$\begin{array}{c}\text { Mind-body } \\
\text { practice } \\
\text { users } \\
(\mathbf{n}=\mathbf{5 5})\end{array}$} & \multirow[t]{2}{*}{ P-value } & \multicolumn{2}{|c|}{$\begin{array}{c}\text { Non-CM } \\
\text { practitioner } \\
\text { service users } \\
\quad(\mathbf{n}=152)\end{array}$} & \multicolumn{2}{|c|}{$\begin{array}{c}\text { CM } \\
\text { practitioner } \\
\text { service users } \\
(\mathbf{n}=\mathbf{1 4 1})\end{array}$} & \multirow[t]{2}{*}{ P-value } \\
\hline & $\mathrm{n}$ & $\%$ & $\mathrm{n}$ & $\%$ & & $\mathrm{n}$ & $\%$ & $\mathrm{n}$ & $\%$ & & $\mathrm{n}$ & $\%$ & $\mathrm{n}$ & $\%$ & & $\mathrm{n}$ & $\%$ & $\mathrm{n}$ & $\%$ & \\
\hline Comorbid conditions & & & & & & & $\sqrt{21}$ & & & & & & & & & & & & & \\
\hline Cardiovascular disorder & 337 & 19.5 & 108 & 36.9 & $<0.001 *$ & 44 & 41.1 & 64 & 34.4 & 0.251 & 93 & 39.1 & 15 & 27.3 & 0.102 & 60 & 39.5 & 48 & 34.0 & 0.336 \\
\hline Diabetes-any & 139 & 8.1 & 37 & 12.6 & $0.010 *$ & 16 & 15.0 & 21 & 11.3 & 0.363 & 29 & 12.2 & 8 & 14.5 & 0.635 & 18 & 11.8 & 19 & 13.5 & 0.674 \\
\hline Cancer-any & 108 & 6.3 & 24 & 8.2 & 0.216 & 9 & 8.4 & 15 & 8.1 & 0.917 & 20 & 8.4 & 4 & 7.3 & 0.783 & 12 & 7.9 & 12 & 8.5 & 0.848 \\
\hline Female reproductive disorder & 74 & 4.3 & 38 & 13.0 & $<0.001 *$ & 14 & 13.1 & 24 & 12.9 & 0.965 & 29 & 12.2 & 9 & 16.4 & 0.406 & 14 & 9.2 & 24 & 17.0 & 0.047 \\
\hline Respiratory disorder & 265 & 15.4 & 88 & 30.0 & $<0.001 *$ & 36 & 33.6 & 52 & 28.0 & 0.306 & 67 & 28.2 & 21 & 38.2 & 0.144 & 45 & 29.6 & 43 & 30.5 & 0.868 \\
\hline Male reproductive disorder & 35 & 2.0 & 13 & 4.4 & $0.012 *$ & 5 & 4.1 & 8 & 4.3 & 0.882 & 12 & 5.0 & 1 & 1.8 & 0.295 & 6 & 3.9 & 7 & 5.0 & 0.673 \\
\hline Mental health disorder & 472 & 27.3 & 169 & 57.7 & $<0.001 *$ & 69 & 64.5 & 100 & 53.8 & 0.074 & 133 & 55.9 & 36 & 65.5 & 0.195 & 84 & 55.3 & 85 & 60.3 & 0.385 \\
\hline Musculoskeletal disorder & 205 & 11.9 & 112 & 38.2 & $<0.001 *$ & 39 & 36.4 & 73 & 39.2 & 0.635 & 91 & 38.2 & 21 & 38.2 & 0.994 & 58 & 38.2 & 54 & 38.3 & 0.980 \\
\hline Other chronic illness & 122 & 7.1 & 26 & 8.9 & 0.273 & 7 & 6.5 & 19 & 10.2 & 0.287 & 20 & 8.4 & 6 & 10.9 & 0.556 & 11 & 7.2 & 15 & 10.6 & 0.306 \\
\hline \multicolumn{21}{|l|}{ Specific GIDs } \\
\hline Irritable bowel syndrome & n.a. & n.a. & 104 & 35.5 & n.a. & 37 & 34.6 & 67 & 36.0 & 0.804 & 84 & 35.3 & 20 & 36.4 & 0.881 & 50 & 32.9 & 54 & 38.3 & 0.334 \\
\hline
\end{tabular}




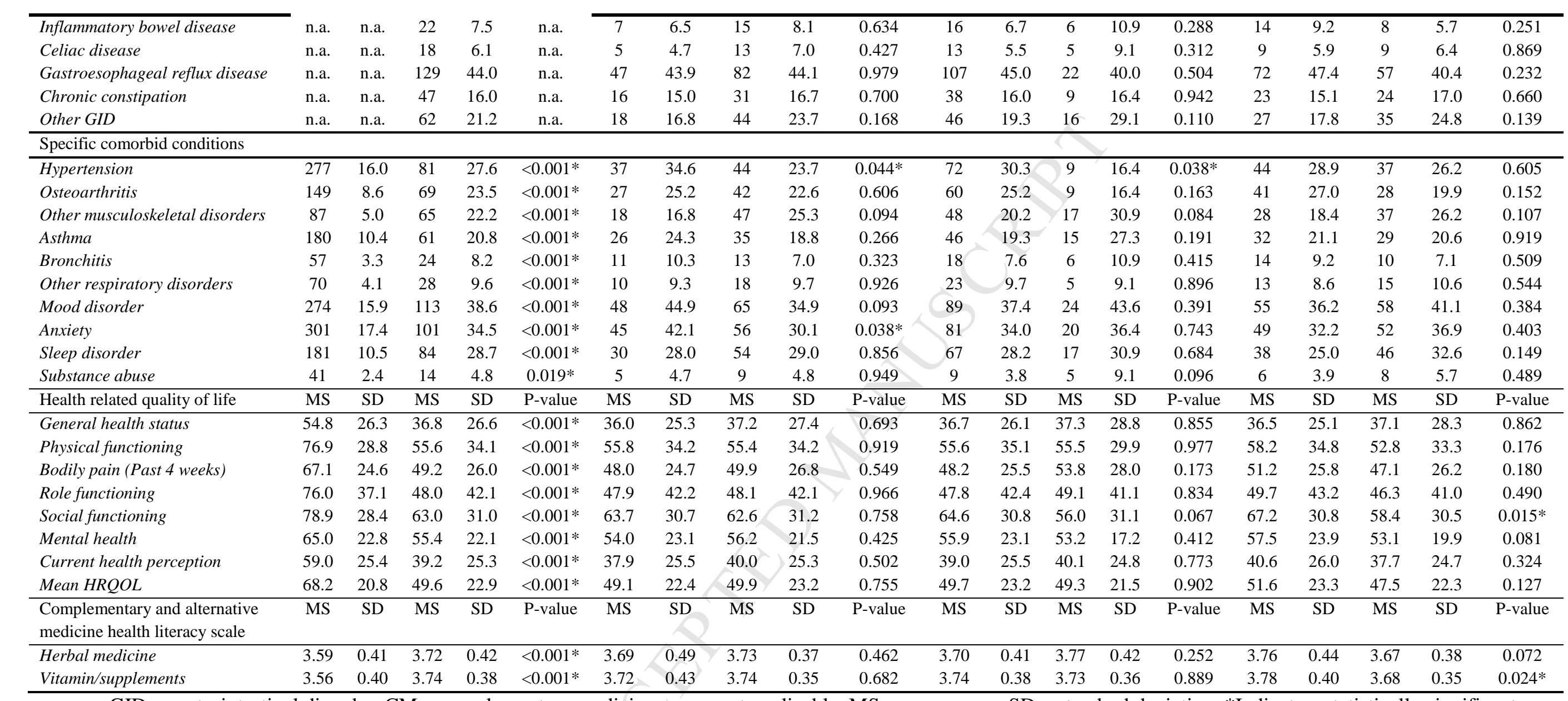

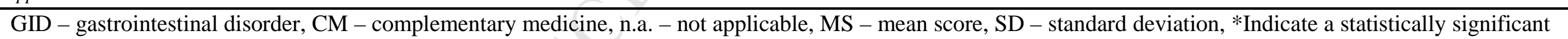

difference between

the

comparison

group

$(p<0.05)$. 


\section{Table 3}

Prevalence of conventional and complementary health services and products utilisation by GID $(\mathrm{n}=293)$ and no-GID $(\mathrm{n}=1,726)$ participants in the last 12 months.

\section{Prevalence of conventional health services and medicinal products use}

\begin{tabular}{|c|c|c|c|c|c|}
\hline \multirow[t]{2}{*}{ Practitioner/Product type } & \multicolumn{2}{|c|}{$\begin{array}{l}\text { GID group } \\
(\mathbf{n}=\mathbf{2 9 3})\end{array}$} & \multicolumn{2}{|c|}{$\begin{array}{c}\text { No-GID group } \\
\quad(\mathbf{n}=1,726)\end{array}$} & \multirow[t]{2}{*}{ P-value } \\
\hline & $\mathrm{n}$ & $\%$ & $\mathrm{n}$ & $\%$ & \\
\hline \multicolumn{6}{|l|}{ Medical doctor } \\
\hline General practitioner* & 285 & 97.3 & 1471 & 85.2 & $<0.001$ \\
\hline Specialist doctor* & 200 & 68.3 & 639 & 37.0 & $<0.001$ \\
\hline Hospital doctor* & 127 & 43.3 & 441 & 25.6 & $<0.001$ \\
\hline \multicolumn{6}{|l|}{ Allied health } \\
\hline Pharmacist* & 261 & 89.1 & 1283 & 74.3 & $<0.001$ \\
\hline Physiotherapist* & 86 & 29.4 & 349 & 20.2 & $<0.001$ \\
\hline Counsellor/psychologist* & 87 & 29.7 & 331 & 19.2 & $<0.001$ \\
\hline Community nurse* & 50 & 17.1 & 154 & 8.9 & $<0.001$ \\
\hline \multicolumn{6}{|l|}{ Pharmaceuticals } \\
\hline Prescription-only* & 266 & 90.8 & 1236 & 71.6 & $<0.001$ \\
\hline Over-the-counter* & 229 & 78.2 & 1120 & 64.9 & $<0.001$ \\
\hline
\end{tabular}

Prevalence of CM practitioner services, CM products and mind-body practices use

\begin{tabular}{|c|c|c|c|c|c|}
\hline \multirow[t]{2}{*}{ Practitioner/Product type } & \multicolumn{2}{|c|}{$\begin{array}{c}\text { GID group } \\
(\mathbf{n}=\mathbf{2 9 3})\end{array}$} & \multicolumn{2}{|c|}{$\begin{array}{l}\text { No- GID group } \\
\quad(\mathbf{n}=\mathbf{1 , 7 2 6})\end{array}$} & \multirow[t]{2}{*}{ P-value } \\
\hline & $\mathrm{n}$ & $\%$ & $\mathrm{n}$ & $\%$ & \\
\hline \multicolumn{6}{|l|}{$\mathrm{CM}$ practitioner } \\
\hline Massage therapist* & 79 & 27.0 & 339 & 19.6 & 0.004 \\
\hline Chiropractor* & 52 & 17.7 & 202 & 11.7 & 0.004 \\
\hline Yoga teacher & 22 & 7.5 & 158 & 9.2 & 0.361 \\
\hline Acupuncturist* & 32 & 10.9 & 127 & 7.4 & 0.036 \\
\hline Naturopath & 21 & 7.2 & 105 & 6.1 & 0.478 \\
\hline Osteopath* & 28 & 9.6 & 82 & 4.8 & 0.001 \\
\hline TCM practitioner & 12 & 4.1 & 95 & 5.5 & 0.320 \\
\hline Aromatherapist & 13 & 4.4 & 66 & 3.8 & 0.617 \\
\hline Homeopath & 7 & 2.4 & 61 & 3.5 & 0.315 \\
\hline \multicolumn{6}{|l|}{$\mathrm{CM}$ products } \\
\hline Vitamins/mineral supplements $*$ & 179 & 61.1 & 787 & 45.6 & $<0.001$ \\
\hline Aromatherapy oils & 33 & 11.3 & 191 & 11.1 & 0.921 \\
\hline Western/Chinese herbal medicine & 19 & 6.5 & 172 & 10.0 & 0.060 \\
\hline Homeopathy* & 9 & 3.1 & 129 & 7.5 & 0.006 \\
\hline Flower essences* & 13 & 4.4 & 138 & 8.0 & 0.032 \\
\hline \multicolumn{6}{|l|}{ Mind-body practice } \\
\hline Yoga/tai chi* & 21 & 7.2 & 216 & 12.5 & 0.009 \\
\hline Relaxation/meditation & 48 & 16.4 & 272 & 15.8 & 0.787 \\
\hline
\end{tabular}


GID - gastrointestinal disorder, $\mathrm{CM}$ - complementary medicine, *Indicates a statistical significant difference between GID and no-GID groups $(\mathrm{p}<0.05)$, TCM - traditional Chinese medicine. 


\section{Table 4}

Out-of-pocket expenditure on each type of conventional and complementary health services and products by GID and no-GID participants over the last 12 months.

\begin{tabular}{|c|c|c|c|c|c|c|}
\hline \multirow[t]{2}{*}{ Type of medicinal products } & \multicolumn{2}{|c|}{$\begin{array}{l}\text { Total reported expenses in year 2016- } \\
\qquad 2017 \text { (AUD) }\end{array}$} & \multirow{2}{*}{$\begin{array}{c}\text { Estimated total } \\
\text { annual expenses } \\
\text { for Australian } \\
\text { population with } \\
\text { GID (AUD) } \\
(\mathrm{n}=2,556,411)^{\mathrm{a}}\end{array}$} & \multirow{2}{*}{$\begin{array}{c}\text { Mean annual } \\
\text { expense in no-GID } \\
\text { participants (AUD) } \\
\text { Per CM product user } \\
\qquad(\mathrm{n}=830)\end{array}$} & \multirow{2}{*}{$\begin{array}{l}\text { Mean annual expense } \\
\text { in GID participants } \\
(\mathrm{AUD}) \\
\text { Per CM product user } \\
\qquad(\mathrm{n}=186)\end{array}$} & \multirow[t]{2}{*}{ P-value } \\
\hline & $\begin{array}{l}\text { All surveyed } \\
\text { participants }(n=2,019)\end{array}$ & $\begin{array}{l}\text { GID participants } \\
\qquad(\mathrm{n}-=293)\end{array}$ & & & & \\
\hline \multicolumn{7}{|l|}{ Pharmaceuticals } \\
\hline Prescription-only* & $206,761.69$ & $52,721.49$ & $459,992,481.13$ & 105.53 & 197.92 & 0.001 \\
\hline Over-the-counter* & $79,798.05$ & $17,454.00$ & $152,285,316.02$ & 48.19 & 71.09 & 0.015 \\
\hline Total & $286,559.74$ & $70,175.49$ & $612,277,797.15$ & 153.72 & 269.01 & \\
\hline \multicolumn{7}{|l|}{ CM products } \\
\hline Vitamins/mineral supplements & $88,297.20$ & $18,849.00$ & $164,456,624.37$ & 83.29 & 100.61 & 0.278 \\
\hline Aromatherapy oils & $10,381.00$ & $2,913.00$ & $25,415,785.81$ & 8.90 & 15.66 & 0.064 \\
\hline Western/Chinese herbal medicine & $11,534.00$ & $1,365.00$ & $11,909,559.78$ & 12.12 & 7.34 & 0.094 \\
\hline Homeopathy & $7,239.00$ & 303.00 & $2,643,660.52$ & 8.26 & 1.63 & 0.146 \\
\hline Flower essences & $5,107.00$ & 380.00 & $3,315,481.84$ & 5.58 & 2.05 & 0.062 \\
\hline Total & $122,558.20$ & $23,810.00$ & $207,741,112.32$ & 118.15 & 127.29 & \\
\hline \multirow[t]{2}{*}{ Type of healthcare professionals } & $\begin{array}{r}\text { Total reported expen } \\
2017(\mathrm{~A}\end{array}$ & $\begin{array}{l}\text { es in year 2016- } \\
\text { JD) }\end{array}$ & $\begin{array}{l}\text { Estimated total } \\
\text { annual expenses } \\
\text { for Australian } \\
\text { population with }\end{array}$ & $\begin{array}{c}\text { Mean annual } \\
\text { expense in no-GID } \\
\text { participants (AUD) }\end{array}$ & $\begin{array}{c}\text { Mean annual expense } \\
\text { in GID participants } \\
\text { (AUD) }\end{array}$ & P-valt \\
\hline & $\begin{array}{c}\text { All surveyed } \\
\text { participants }(n=2,019)\end{array}$ & $\begin{array}{l}\text { GID participants } \\
\qquad(\mathrm{n}-=293)\end{array}$ & $\begin{array}{c}\text { GID }(\text { AUD }) \\
(\mathrm{n}=2,556,411)^{\mathrm{a}}\end{array}$ & $\begin{array}{l}\text { Per CM practitioner } \\
\text { service user }(n=585)\end{array}$ & $\begin{array}{l}\text { Per CM practitioner } \\
\text { service user }(n=141)\end{array}$ & \\
\hline \multicolumn{7}{|l|}{ Conventional health practitioner } \\
\hline General practitioner & $263,224.06$ & $17,912.00$ & $156,281,344.14$ & 351.02 & 103.21 & 0.188 \\
\hline Specialist doctor & $243,453.05$ & $39,786.00$ & $347,130,948.96$ & 205.31 & 187.76 & 0.871 \\
\hline Hospital doctor & $72,500.00$ & $6,439.00$ & $56,179,967.33$ & 58.96 & 31.81 & 0.265 \\
\hline
\end{tabular}




\begin{tabular}{|c|c|c|c|c|c|c|}
\hline Pharmacist & n.a. & n.a. & n.a. & n.a. & n.a. & n.a. \\
\hline Community nurse & $7,185.00$ & 890.00 & $7,765,207.47$ & 10.38 & 5.04 & 0.155 \\
\hline Physiotherapist & $39,963.37$ & $6,518.00$ & $56,869,238.56$ & 41.85 & 33.70 & 0.434 \\
\hline Counsellor/psychologist & $53,556.00$ & $6,475.00$ & $56,494,065.61$ & 42.35 & 33.72 & 0.457 \\
\hline Total & $679,881.48$ & $78,020.00$ & $680,720,772.08$ & 709.87 & 395.24 & \\
\hline CM practitioner & & & & (1) & & \\
\hline Massage therapist & $40,961.00$ & $8,044.00$ & $70,183,515.65$ & 56.36 & 57.05 & 0.959 \\
\hline Chiropractor & $32,738.00$ & $7,209.00$ & $62,898,180.54$ & 43.64 & 51.13 & 0.637 \\
\hline Yoga teacher* & $9,990.00$ & 762.00 & $6,648,413.59$ & 15.77 & 5.40 & 0.045 \\
\hline Acupuncturist & $14,492.00$ & $2,420.00$ & $21,114,384.37$ & 20.71 & 17.16 & 0.588 \\
\hline Naturopath & $15,708.00$ & $3,878.00$ & $33,835,364.70$ & 20.22 & 27.50 & 0.518 \\
\hline Osteopath & $9,833.00$ & $1,860.00$ & $16,228,411.13$ & 13.63 & 13.19 & 0.910 \\
\hline TCM practitioner & $9,147.00$ & $1,179.00$ & $10,286,718.67$ & 13.62 & 8.36 & 0.241 \\
\hline Aromatherapist & $11,881.00$ & $1,553.00$ & $13,549,850.80$ & 17.65 & 11.01 & 0.501 \\
\hline Homeopath & $7,892.00$ & $1,385.00$ & $12,084,058.82$ & 11.12 & 9.82 & 0.869 \\
\hline Western herbalist & $7,545.00$ & $1,425.00$ & $12,433,056.91$ & 10.48 & 10.11 & 0.961 \\
\hline Total & $160,187.00$ & $29,715.00$ & $259,261,955.17$ & 223.20 & 210.73 & \\
\hline \multirow{3}{*}{ Type of mind-body practices } & \multirow{2}{*}{\multicolumn{2}{|c|}{$\begin{array}{l}\text { Total reported expenses in year 2016- } \\
2017 \text { (AUD) }\end{array}$}} & \multirow{3}{*}{$\begin{array}{c}\text { Estimated total } \\
\text { annual expenses } \\
\text { for Australian } \\
\text { population with } \\
\text { GID (AUD) } \\
(\mathrm{n}=2,556,411)^{\mathrm{a}}\end{array}$} & \multirow{3}{*}{$\begin{array}{c}\text { Mean annual } \\
\text { expense in no-GID } \\
\text { participants (AUD) } \\
\text { Per mind-body } \\
\text { practice user }(n=322)\end{array}$} & \multirow{3}{*}{$\begin{array}{c}\text { Mean annual expense } \\
\text { in GID participants } \\
\text { (AUD) } \\
\text { Per mind-body } \\
\text { practice user }(\mathrm{n}=55)\end{array}$} & \multirow{3}{*}{ P-value } \\
\hline & & & & & & \\
\hline & $\begin{array}{c}\text { All surveyed } \\
\text { participants }(n=2,019)\end{array}$ & $\begin{array}{l}\text { GID participants } \\
(\mathrm{n}-=293)\end{array}$ & & & & \\
\hline Yoga/tai chi* & $13,138.00$ & 581.00 & $5,069,197.24$ & 37.82 & 10.56 & 0.044 \\
\hline \multirow{2}{*}{ Relaxation/meditation } & $10,491.00$ & $1,316.00$ & $11,482,037.12$ & 26.80 & 23.78 & 0.804 \\
\hline & $23,629.00$ & $1,897.00$ & $16,551,234.36$ & 64.62 & 34.34 & \\
\hline
\end{tabular}

GID - gastrointestinal disorder, CM - complementary medicine, ${ }^{\mathrm{a}}$ The estimated number of Australian population with a GID (n=2,556,411) was calculated based on Australian census figures in year 2016 for Australian adults aged 20 years or above $(n=17,615,676)$ and the reported prevalence of GID in this study (14.51\%), *Indicates a significant difference between GID and no-GID groups $(\mathrm{p}<0.05)$, n.a. - not applicable as pharmacist consultation is usually free of charge, TCM traditional Chinese medicine. 
Table 5

Logist

\begin{tabular}{|c|c|c|c|c|c|c|c|c|c|}
\hline \multirow{2}{*}{ Characteristics } & \multicolumn{3}{|c|}{ CM products use } & \multicolumn{3}{|c|}{ Mind-body practices use } & \multicolumn{3}{|c|}{ CM practitioner services use } \\
\hline & OR & $95 \% \mathrm{CI}$ & $\mathrm{P}$-value & OR & $95 \% \mathrm{CI}$ & P-value & OR & $95 \% \mathrm{CI}$ & P-value \\
\hline $\begin{array}{l}\text { Gender } \\
(0=\text { female, } 1=\text { male })\end{array}$ & 0.50 & $0.29-0.87$ & $0.014^{*}$ & 0.89 & $0.43-1.85$ & 0.758 & 1.28 & $0.73-2.25$ & 0.381 \\
\hline $\begin{array}{l}\text { Age } \\
\text { (Low to high) }\end{array}$ & 1.17 & $0.95-1.44$ & 0.141 & 0.69 & $0.53-0.89$ & $0.004 *$ & 0.74 & $0.60-0.91$ & $0.005^{*}$ \\
\hline $\begin{array}{l}\text { Financial manageability } \\
\text { (Difficult to easy) }\end{array}$ & 1.09 & $0.78-1.51$ & 0.624 & 0.95 & $0.63-1.42$ & 0.791 & 1.34 & $0.93-1.86$ & 0.082 \\
\hline $\begin{array}{l}\text { Employment status } \\
\text { (Employed to unemployed) }\end{array}$ & 0.81 & $0.67-0.97$ & $0.024 *$ & 1.01 & $0.81-1.26$ & 0.930 & 0.86 & $0.71-1.03$ & 0.097 \\
\hline $\begin{array}{l}\text { Education level } \\
\text { (Low to high) }\end{array}$ & 1.06 & $0.82-1.38$ & 0.639 & 1.44 & $1.01-2.03$ & $0.041 *$ & 1.12 & $0.87-1.45$ & 0.380 \\
\hline $\begin{array}{l}\text { Marital status } \\
\text { (No to in-relationship) }\end{array}$ & 0.98 & $0.81-1.19$ & 0.850 & 1.23 & $0.96-1.56$ & 0.097 & 1.02 & $0.84-1.23$ & 0.882 \\
\hline $\begin{array}{l}\text { Private insurance } \\
(0=\text { no, } 1=\text { yes })\end{array}$ & 0.87 & $0.51-1.49$ & 0.616 & 1.05 & $0.53-2.06$ & 0.900 & 0.62 & $0.36-1.05$ & 0.077 \\
\hline $\begin{array}{l}\text { Health care card } \\
(0=\text { no, } 1=\text { yes })\end{array}$ & 1.13 & $0.63-2.01$ & 0.685 & 0.93 & $0.45-1.91$ & 0.834 & 0.79 & $0.44-1.40$ & 0.416 \\
\hline $\begin{array}{l}\text { Health-related quality of life } \\
\text { (Low to high) }\end{array}$ & 1.00 & $0.98-1.01$ & 0.389 & 1.00 & $0.98-1.01$ & 0.670 & 0.98 & $0.97-0.99$ & $0.001 *$ \\
\hline Constant & 5.55 & n.a. & 0.121 & 0.25 & n.a. & 0.316 & 10.24 & n.a. & $0.038^{*}$ \\
\hline
\end{tabular}

ic regres sion report ing the predic tors of CM produ cts, mindbody practi ces and practitioner services use in GID participants $(n=293)$. 
CM - complementary medicine, OR - odds ratio, CI - confidence interval, n.a. - not applicable, *Indicate a statistical significance (p<0.05) 


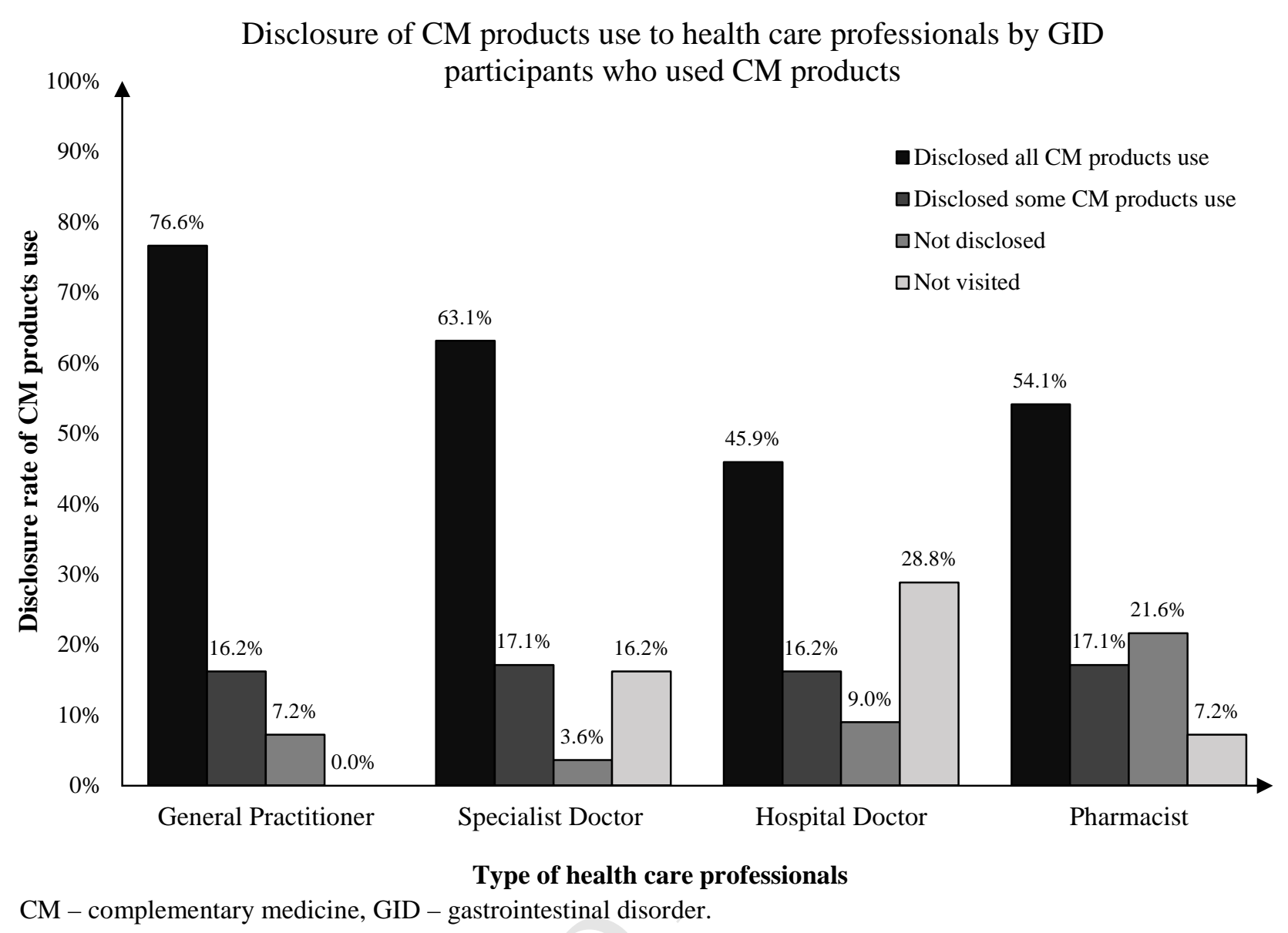

Figure 1. Disclosure rate of CM products use by CM product users with a GID ( $n=111)$. 